\title{
Modelos teóricos de implicación educativa familiar: responsabilidades compartidas entre centros educativos, familias y comunidad
}

\author{
Lucía Álvarez Blanco \\ Universidad de Oviedo - España
}

\begin{abstract}
RESUMEN
Los logros escolares y la calidad educativa que reciben los menores dependen, en gran medida, de la actuación que desarrollen los dos primeros agentes de socialización, la familia y el centro escolar. Los factores y condicionantes que operan diferencialmente en ellos para contribuir a la formación de los menores son variados y complejos. Sin embargo, la investigación evidencia que la frecuencia y calidad de las relaciones que se establezcan entre ellos contribuye a mejorar la eficacia educativa de ambos contextos y genera efectos positivos en el desarrollo integral del alumnado y en su rendimiento escolar, facilitando así la generación de capital humano y social. Este artículo incluye una revisión de algunos modelos teóricos en el estudio de la implicación educativa familiar y de las relaciones que cabe establecer entre los entre los centros escolares, las familias y las entidades comunitarias para promover esta colaboración. En concreto, se presenta: 1) Modelo Ecológico Sistémico; 2) Modelo de Esferas Superpuestas de Influencia; 3) Modelo "Syneducation"; 4) Modelo Causal y Específico de Implicación Parental; 5) Modelo Motivacional y de Conceptualización Multidimensional y 6) Modelo Bipiramidal Jerarquizado. Se concluye subrayando los beneficios de esta alianza educativa para facilitar el adecuado logro escolar de los y las estudiantes, su desarrollo integral, una convivencia más positiva en el centro y en el hogar y, por último, una mayor calidad educativa.
\end{abstract}

Palabras Clave: Cooperación familia-escuela-comunidad, educación familiar, modelos teóricos, educación de calidad.

\section{Theoretical models of family educational involvement: shared responsibilities between the school, the family and the community}

\section{ABSTRACT}

School achievements and the quality of education that children receive, rely heavily on the actions carried out by the first two agents of socialization, the family and the school. There are varied and complex factors and constraints affecting these two agents and, consequently, children\&\#39;s education. However, research shows that the frequency and quality of the relationships established between them helps improving the educational effectiveness in both contexts; thus, generating positive effects on children's development and on their school performance. It provides, then, human and social capital. This article reviews some theoretical models on family educational involvement and on schools, families and communities collaboration. In particular, the article addresses: 1) Ecological Systems Model; (2) Overlapping Spheres of Influence Model; (3) "Syneducation" Model; 4) Causal and Specific Model of Parental Involvement; 5) Motivational and Multidimensional Construct Model, and 6) Hierarchic Bi-pyramidal Model. The article concludes underlining the benefits of schools, families and communities partnership to facilitate the proper school achievement of students, their full development, more positive coexistence both at school and at home and, finally, a greater educational quality.

Keywords: Home-school Partnership, family education, conceptual/theoretical frameworks, educational quality.

\section{Introducción}

La sociedad globalizada y de la información y la comunicación que caracteriza actualmente a los países desarrollados exige a los ciudadanos una constante adaptación (Gertrudis, Gértrudix y Álvarez, 2016; Ramos y Arévalo, 2018). La familia contribuye, como agente de socialización primario (Álvarez y Martínez-González, 2017a) y máxima responsable de la educación de sus hijos
(HoltIs-Unicef, 2017), a desarrollar en ellos competencias que les permiten desenvolverse de modo autónomo y eficaz (Robledo y García, 2011). En este cometido la familia no se encuentra sola sino que cuenta con la colaboración de instituciones, servicios y entidades educativas y sociales (Álvarez y Martínez-González, 2017b; Alves, Assis, Martins y Da Silva, 2017; Rodrigo et al., $\underline{2015}$ ), entre las que destacan los centros escolares. Estos agentes de socialización secundaria (Moreno, 2002), de darse las condicio- 
nes adecuadas, pueden contribuir a compensar desigualdades sociales y a fomentar la inclusión y la equidad (Ainscow, 2016; Parra, 2011; Simón, Giné y Echeita, 2016).

Esta complementariedad educativa se verá reforzada en la medida en que los centros escolares promuevan relaciones de colaboración con las familias, que faciliten su implicación en el proceso educativo y de aprendizaje de sus hijos e hijas (Gârț, 2017). Las investigaciones realizadas al respecto indican que entre los beneficios que cabe destacar de esta relación sobresalen el fomento de la inclusión (Deslandés, 2015), la adaptación escolar y social del alumnado (Coe, Davies y Sturge-Apple, 2017), la mejora de su rendimiento académico (Valle et al., 2018), el ajuste psicosocial, sobre todo en los y las adolescentes (Álvarez et al., 2015; ఏiménez y Moreno, 2015), o la prevención del abandono, del absentismo y del fracaso escolar (Álvarez y Martínez-González, 2016; Fernández-Zabala, Goñi, Camino y Zulaika, 2016; Méndez y Cerezo, 2018). Por ello, se entiende esta cooperación como una estrategia para conseguir una educación de los y las menores de calidad y para generar, en consecuencia, capital humano, social y cultural en la sociedad (De la Riva y Moreno, 2018).

Sin embargo, en ocasiones se observa en los centros escolares una actitud ambivalente hacia las familias (Álvarez, 2006), caracterizada, por una parte, por percibirla como aliada clave en la consecución de los objetivos educativos con respecto al alumnado, y, por otra, por un sentimiento de intrusión en el ejercicio profesional docente (Rivas y Ugarte, 2014). Por otra parte, se advierte cada vez más que en las entrevistas tutoriales con el profesorado, los padres y madres tienden a esperar información sobre pautas educativas a utilizar con sus hijos e hijas para ejercer eficazmente su rol parental (Redding, 2006) y poder contribuir adecuadamente a su desarrollo personal y escolar (Martínez-González y Pérez, 2006; Rodrigo et al., 2015; Rodrigo, Martínez-González y Rodríguez-Ruiz, 2018). Por ello, y en respuesta al principio de subsidiariedad en educación (Aguilera y Rodríguez, 2010), parece obvio que tanto los centros escolares como las familias necesitan cooperar para procurar la mejor educación de los menores. El modo en que esta cooperación se materializa ha sido analizada desde distintas perspectivas y aproximaciones teóricas que se exponen a continuación: 1) Modelo Ecológico Sistémico; 2) Modelo de Esferas Superpuestas de Influencia; 3) Modelo "Syneducation"; 4) Modelo Causal y Específico de Implicación Parental; 5) Modelo Motivacional y de Conceptualización Multidimensional y 6) Modelo Bipiramidal Jerarquizado.

\section{Modelo Ecológico Sistémico del Desarrollo Humano (Bron- fenbrenner, 1987)}

De acuerdo con Intxausti (2010), la Teoría Ecológica del Desarrollo Humano formulada por Bronfenbrenner (1987) se fundamenta en los supuestos de la Teoría General de Sistemas (Bertalanffy, 1968), desde la que se entiende que un sistema está integrado por un conjunto de elementos que interaccionan entre sí y que se influyen mutuamente. En el modelo Ecológico Sistémico se destacan varios subsistemas ambientales que influyen en el desarrollo del sujeto a través de las influencias directas o indirectas que ejercen sobre él; destacando, además, la interacción entre estos subsistemas y el componente bidireccional de estas relaciones (Bronfenbrenner, 1999).

La Figura 1 ofrece una representación visual de este flujo de relaciones en el que, mediatizado por el factor temporal -Time-, se otorga especial relevancia al sujeto en desarrollo. Este queda representado en el modelo con la letra " $\mathrm{P}$ " (sistema ontogenético, menor, alumno/a o hijo/a en el caso que nos ocupa), emergiendo entonces la denominación de "Bioecológico" que permite complementar así la tradicional aproximación ecológica de este autor insistiendo en que "las propiedades de la persona y del ambiente interactúan para producir constancia y cambio en las características biopsicológicas de la persona a lo largo de su vida" (Gifre y Esteban, 2012, p.84). Como se advierte, el componente "Bio" incluye en el análisis sistémico el plano biológico, cognitivo, emocional y conductal del individuo.

Con ello, en la lectura e interpretación de esta imagen destacan dos zonas claramente diferenciadas: la derecha, que ilustra el conjunto de sistemas concéntricos propio del modelo Ecológico (sistema ontogenético- P-; microsistema, exosistema, macrosistema y mesosistema) y la izquierda, centrada en una ampliación del citado microsistema. Así, en este privilegiado escenario acontecen interacciones e influencias bidireccionales entre el sujeto en desarrollo y otros agentes de socialización como las familias y los centros escolares, aflorando en este intercambio dinámico, como se desprende de la Tabla 1, objetos, elementos de naturaleza simbólica y personas junto al organismo biopsicosocial activo al que se acaba de aludir (Bronfenbrenner, 2005; Bronfenbrenner y Morris, 1998).

De manera más específica, los distintos subsistemas a que se hace referencia en este modelo se describen en la Tabla 1.

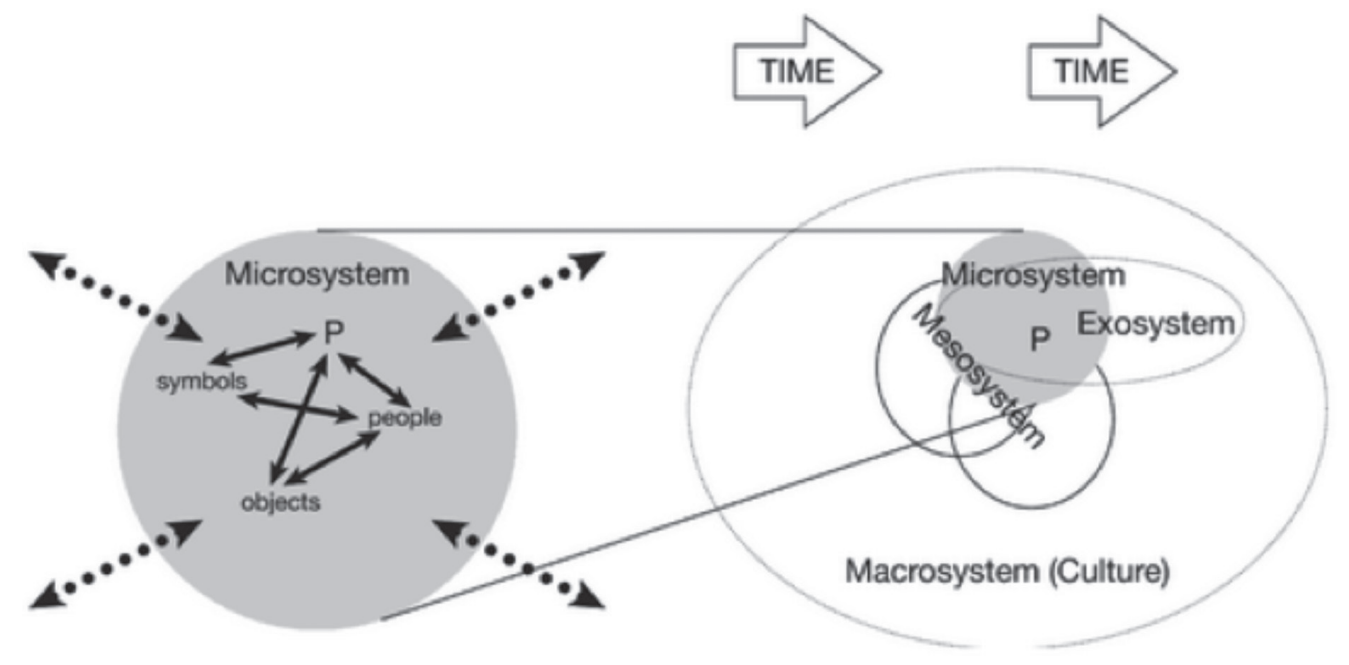

Figura 1. Modelo Bioecológico de Bronfenbrenner. Fuente: Hayes, O’Toole y Halpenny, (2017, p.23). 
Tabla 1.

Subsistemas que integran el Modelo Bioecológico de Bronfenbrenner

Sistema ontogenético. Definido como los rasgos físico-biológicos (sexo, edad...), cognitivos, emocionales, de personalidad, intereses y expectativas, etc., específicos del sujeto en desarrollo. En el caso del alumnado que presenta bajos rendimientos escolares se advierte una baja autoestima (Calero, Choi y Waisgrais, 2010), especialmente académica, desmotivación ante el estudio y bajo esfuerzo, atribuciones de fracaso a factores endógenos en las chicas -falta de habilidad o esfuerzo- y exógenos en los chicos y las chicas (labor docente o suerte- (Cerezo y Casanova, 2004).

Microsistema. Se trata de los entornos convivenciales más próximos donde la persona establece sus relaciones más tempranas, íntimas y cercanas. Como ejemplos se apuntan la familia y el centro escolar -compañeros, profesorado...- (Grau, Pina y Sancho, 2011) si bien el ámbito familiar parece ser el más determinante ( $\mathrm{Xu} \mathrm{y} \mathrm{Filler,} \mathrm{2008).} \mathrm{En} \mathrm{este} \mathrm{análisis} \mathrm{del} \mathrm{centro} \mathrm{cabe}$ considerar indicadores como la dotación de recursos e instalaciones, ratio y horario de clases, metodología docente, señas de identidad del centro y curriculum escolar, criterios y sistemas de evaluación, liderazgo educativo y equipo de profesionales, participación familiar en los órganos de la institución académica, etc. (Marchesi y Pérez, 2003). Con ello, es urgente atender el modo en que ambos agentes de socialización se perciben y comunican puesto que es justamente esta intersección la clave del desempeño psicopedagógico y del éxito escolar.

Exosistema. Representa las influencias ejercidas sobre el sujeto en desarrollo desde contextos formales e informales en los que este no participa directamente. Como ejemplos que pueden condicionar la calidad de la participación parental en la educación de sus hijos e hijas adolescentes sobresale las particularidades de la relación con la familia extensa, amistades, idiosincrasia del entorno laboral de los progenitores, vecindario, medios de comunicación, servicios sociales, de salud, justicia, etc. (Martínez-González y Álvarez, 2005; García, Hernández, Parra, y Gomáriz, 2016).
Macrosistema. Aglutina el sistema de creencias, valores culturales, costumbres, sistema económico, filosófico-religioso, político y normas de un grupo social y cultural concreto. Es el sistema más distante de la persona en desarrollo (Díaz-Aguado, Martínez y Ordóñez, 2013) en que las conductas de esta se ven afectadas por este escenario sistémico mediante un proceso de filtrado transversal permanente a través de los diversos sistemas. Con ello, más que tratarse de un contexto específico podría definirse como un ambiente holístico (Martínez-González y Pérez, 2004) que mediatiza y otorga homogeneidad a los niveles citados con anterioridad.

Mesosistema. Refleja las interacciones e influencias recíprocas que emergen entre dos o más de los entornos o subsistemas citados anteriormente.

De entre estos subsistemas, destacamos en este estudio el Mesosistema, entendido como el sistema de relaciones bidireccionales entre los restantes sistemas; entre ellos los microsistemas Familia y Centro Escolar, cuya interacción y relación positiva posibilitará crear las condiciones adecuadas para favorecer el desarrollo integral de los niños y niñas. A ello contribuirán también las características del exositema, representadas por las circunstancias de su entorno comunitario.

A estos subsistemas cabe añadir el Cronosistema, que representa la dimensión temporal en el modelo; hace referencia a las condiciones sociohistóricas y a la evolución cultural de la sociedad, así como a las transiciones vitales del ser humano a lo largo de su desarrollo evolutivo.

\section{Modelo de Esferas Superpuestas de Influencia (Epstein, 1990)}

Un importante volumen de investigaciones desarrolladas en las últimas décadas sobre las relaciones que cabe establecer entre los centros escolares, las familias y las entidades comunitarias, toman como referencia este modelo propuesto por Epstein $(1990$, 1995, 2011; Epstein et al., 2002), representado en la Figura 2.

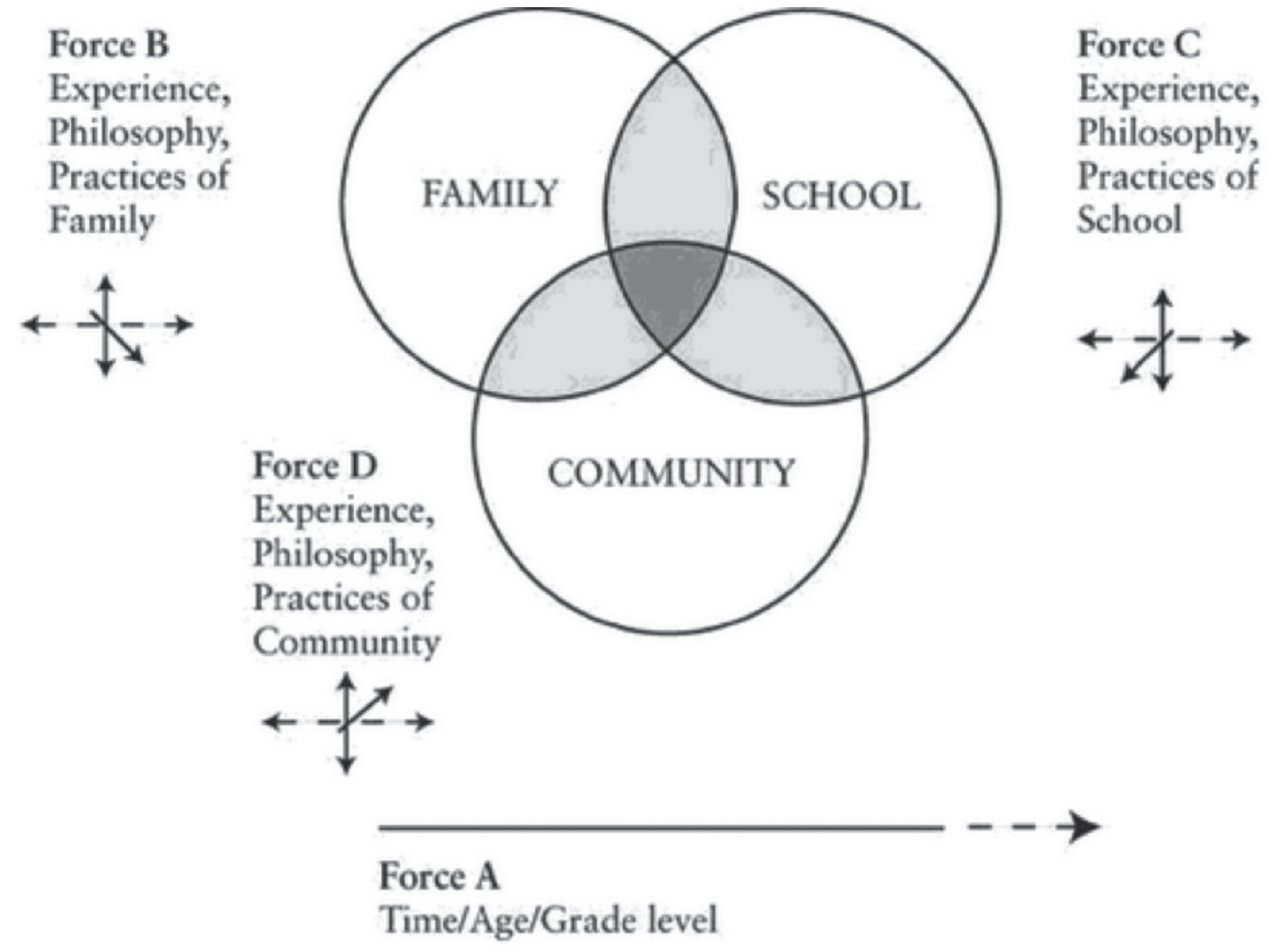

Figura 2. Modelo de Esferas Superpuestas entre la Comunidad, las Familias y los Centros escolares. Fuente: Epstein et al. (2002, p.117). 
Se trata de un enfoque global y holístico sobre la participación en el ámbito escolar (Deslandes, 2015; Epstein, 2011) que incluye cuatros esferas o contextos de aprendizaje (Intxausti, 2010) caracterizados por interaccionar en torno a un espacio central referido al sujeto en desarrollo (estudiante): centro escolar, familia y comunidad.

El modelo se asienta, entre otras, en tres premisas fundamentales: 1) considerar al y la estudiante como el objetivo prioritario de la relación entre los tres contextos, buscando contribuir a su éxito académico y a su desarrollo integral. Para ello se tienen en cuenta, entre otras cosas, aspectos organizativos y metodológicos del centro, programas curriculares y las características de desarrollo y competencias personales de los y las propios estudiantes (Suárez y Vélez, 2018); 2) reconocer el valor que tienen las relaciones de colaboración entre el centro, las familias y las entidades comunitarias para generar efectos positivos no solo en el alumnado, sino también en cada uno de los agentes implicados, optimizando sus propios recursos y potencialidades. Por lo que respecta específicamente al centro escolar y a las familias, las investigaciones sugieren mejoras en sus respectivas dinámicas de convivencia interna (Álvarez y Martínez-González, 2017a, 2017b); y 3) identificar y actuar sobre factores o "fuerzas" que favorecen el acercamiento o distanciamiento entre los centros y las familias. Entre estos factores se encuentran el tiempo disponible para dinamizar esta relación, la etapa escolar del alumnado y su edad (fuerza A) y las experiencias, valores, filosofía y prácticas tanto de las familias (fuerza B), del centro escolar (fuerza C) y de la propia comunidad (fuerza D) (Deslandes, 2001; Epstein, 2002, 2011) (ver Figura 2). La naturaleza y sentido de estas fuerzas determinará la organización e implementación de un mayor o menor número y calidad de actividades colaborativas entre ambos agentes educativos (Fernández-Zabala et al., 2016; Redding, 2006).

La finalidad primordial que se fija en este modelo es fomentar la complementariedad, comunicación y cooperación entre los tres contextos comentados para facilitar al estudiante su proceso de aprendizaje y éxito escolar (Epstein y Sanders, 2006; Fletcher y Silberberg, 2006); ello permitirá prevenir el absentismo, el abandono y el fracaso escolar. Para ello, Epstein (1987) establece seis áreas y prácticas de colaboración (Tabla 2), que aparecen contempladas en un gran número de investigaciones, evidenciando su validez y aceptación internacional (Christenson y Reschly, 2010; Deslandes, 2015; Epstein y Salinas, 2004; Epstein y Sheldon, 2002; Hoover-Dempsey y Sandler, 1995; Intxausti, 2010, entre otros).

Tabla 2.

Áreas de Cooperación entre los Centros Escolares, las Familias y las Entidades Comunitarias según el Modelo de Esferas Superpuestas (Epstein, 1987)

Área 1. Ayuda de los centros escolares a las familias para que estas puedan cumplir con sus responsabilidades básicas respecto a la educación de sus hijos e hijas (Parenting). Remite al ofrecimiento de una ayuda explícita a las familias en el ejercicio de su rol parental, es decir, ante las funciones de crianza y educación de los hijos e hijas: comprensión de su desarrollo evolutivo, satisfacción de las necesidades físico-biológicas, emocionales, materiales (alimentación, vestido, estudio), etc. Reflexionar sobre las características que definen a cada estilo educativo parental y sus efectos en los y las menores_(Fuentes, García, Gracia y Alarcón, 2015) adquieren protagonismo en esta modalidad participativa.

Área 2. Comunicación (Communication). En este caso se alude a una comunicación bidireccional entre padres, madres, tutores y docentes sobre cuestiones como el curriculum y la organización escolar, características personales de los hijos e hijas, progreso académico de los y las estudiantes, expectativas formativas, características sociodemográficas familiares, necesidades parentales, etc.

Área 3: Voluntariado de las familias en actividades del centro (Volunteering). Esta tercera variante remite a la participación voluntaria de la familia en actividades extraescolares, de aula, complementarias o en otros eventos especiales promovidos desde la institución académica. También se contempla aquí el interés de formar y actualizar al profesorado (González, García, Ruiz y Muñoz, 2015) para trabajar con voluntariado o con entidades que apoyen tanto a los estudiantes en su aprendizaje como al centro escolar.

Área 4: Seguimiento del aprendizaje académico en casa (Learning at home). Supone promocionar la implicación y ayuda parental en la realización de las actividades de aprendizaje del hijo o hija, así como los diálogos sobre la vida y jornada escolar, la actitud parental de ánimo y motivación ante el estudio, etc. (Hill y Tyson, 2009). Se apunta asimismo la posibilidad de que el colectivo docente diseñe actividades de aprendizaje para el hogar que promuevan el intercambio, debate familiar, establecimiento de normas y asunción de responsabilidades en la realización de las tareas escolares.

Área 5: Participación de las familias en los órganos de decisión del centro (Decision making). Participación familiar en los órganos de decisión y gestión del centro, como por ejemplo en el Consejo Escolar. También se alude a la implicación efectiva en las Asociaciones de Madres y Padres (Sarramona y Rodríguez, 2010).

Área 6: Colaboración con entidades comunitarias (Collaboration with the community). Finalmente se contempla la coordinación de recursos y servicios en esta tríada de agencias: familia, centro docente y entidades del entorno. A modo de ejemplo, sobresale el intercambio y relación con otros padres y madres del mismo entorno comunitario, la localización de recursos y servicios de la comunidad que puedan servir de ayuda o interés a las familias (actividades y organizaciones culturales, servicios sanitarios...) e incluso la oferta de acciones formativas de capacitación parental y orientación educativa familiar (Martínez-González, Rodríguez-Ruiz, Álvarez-Blanco, y Becedóniz-Vázquez, 2016).

En definitiva, este modelo orienta la praxis de las instituciones escolares para fomentar una auténtica cooperación con las familias y con las entidades comunitarias para promover el éxito académico del alumnado y la prevención del fracaso y del abandono escolar (Epstein y Salinas, 2004).

4. Modelo Syneducation para fomentar la implicación parental en el proceso educativo de los hijos (Mylonakou \& Kekes, 2005)

El término "Syneducation" ha sido introducido por MylonaKou y Kekes $(2005,2007)$ fusionando las palabras "sinergia" y “educación"; su representación se observa en la Figura 3. 


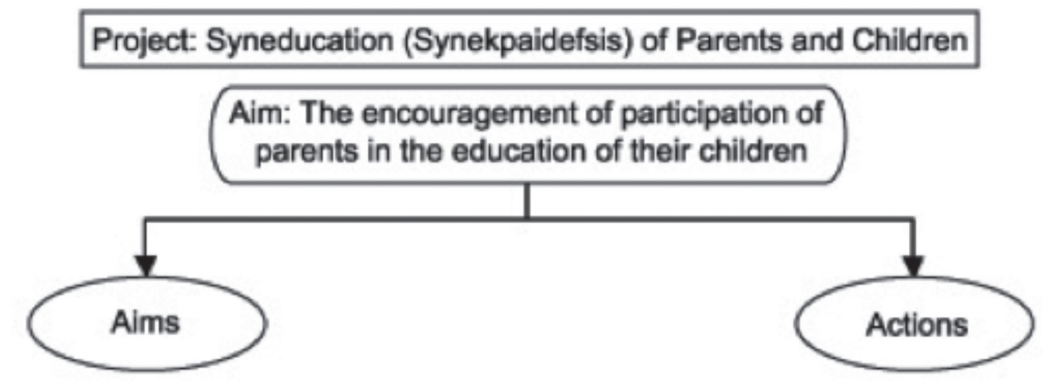

Phase I: Collaborative Action Research

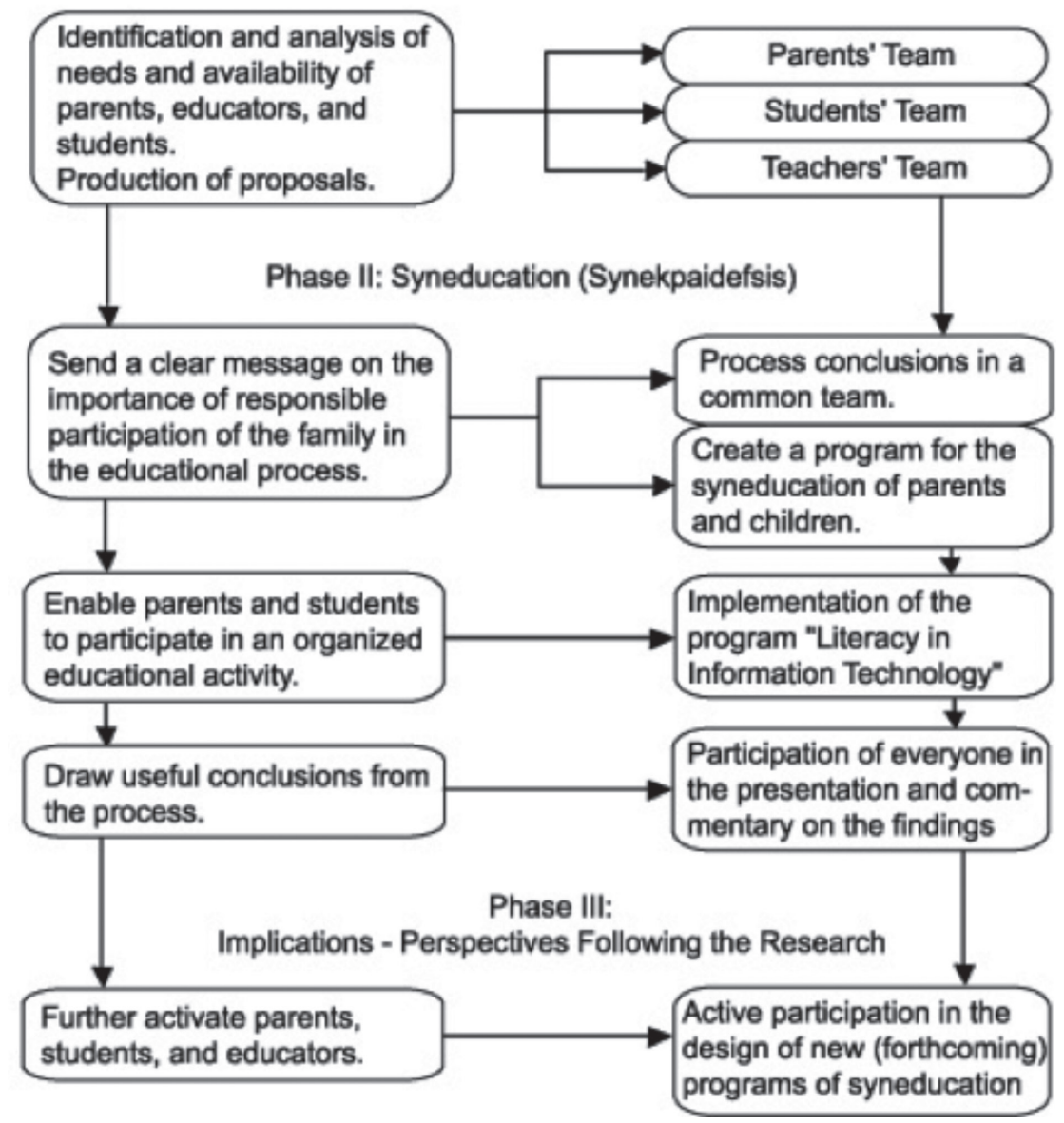

Figura 3. Modelo Syneducation para fomentar la implicación parental en el proceso educativo de los hijos e hijas. Fuente: Mylonakou y Kekes (2005, p.3)

Se trata de un modelo de programa que pretende estimular desde los centros escolares la implicación parental en la educación de sus hijos e hijas transformando potenciales actitudes iniciales de los padres y madres de desinterés o indiferencia, en una adecuada participación y colaboración con sus hijos e hijas en la realización de actividades educativas (Mylonakou y Kekes, 2007). Se concreta en la práctica en tres fases progresivas de acción e investigación cuyas características se resumen en la Tabla 3.

Tabla 3.

Fases a considerar en el Programa Syneducation

Fase 1: Investigación-acción colaborativa. Contempla primeramente un análisis diagnóstico para identificar las necesidades de cooperación entre los centros docentes y las familias, implicando tanto al profesorado, como a los padres, madres y al alumnado.
En segundo lugar recoge las potenciales aportaciones de cada agente para mejorar dicha cooperación. Algunos ejemplos de cómo desarrollar este proceso se encuentran en Martínez (1997); Martínez-González et al. (2000); Martínez-González y Pérez (2006); Martínez-González, Rodríguez-Ruiz, y Gimeno (2010); Martínez-González y San Fabián (2002).

Fase 2: Syneducation. Se insiste aquí en la importancia de que exista una responsabilidad y participación familiar en el proceso de aprendizaje/educación del menor, posibilitando la participación de padres, madres, hijos e hijas en actividades educativas (alfabetización tecnológica, competencias comunicativas y emocionales, hábitos y técnicas de estudio).

Fase 3: Implicaciones y propuestas de futuro. Se cierra el círculo por un lado, reflexionando sobre las implicaciones y aprendizajes derivados de la experiencia y, por otro, con el enunciado de futuras líneas de investigación o programas de intervención sobre las temáticas ya apuntadas. 
De acuerdo con Mylonakou y Kekes (2005), los principales resultados de este modelo son: a) los participantes adquieren experiencia en la utilización de modelos de colaboración, métodos de investigación, toma de decisiones conjunta y desarrollo de habilidades de comunicación; b) el profesorado muestra un especial interés por las dinámicas familiares y su repercusión en el aprendizaje y educación del estudiante; c) el alumnado incrementa su motivación por el aprendizaje; y d) las familias hacen más consciente la importancia de apoyar el proceso de aprendizaje de sus hijos e hijas, evitando adoptar actitudes tanto de indiferencia como de presión o supervisión excesiva del hijo o hija. En definitiva, el modelo promueve la reflexión sobre la implicación educativa familiar y la cooperación entre los centros escolares y las familias, facilitando que los padres y madres y el profesorado puedan asumir nuevos roles tanto en su interacción como adultos, como en la que establecen con los menores (hijos, hijas y alumnado). Se trata en último término, de favorecer un enriquecimiento mutuo entre las partes implicadas, reforzando la comunicación, empatía, confianza y apoyo recíproco, tal como sugieren diversos investigadores (Martínez-González y Pérez, 2004, 2006; Martínez-González, Rodríguez-Ruiz y Gimeno, 2010; Martínez-González y San Fabián, 2002).

\section{Modelo Causal y Específico de Implicación Parental (Hoo-} ver-Dempsey y cols., 1995)

Esta aproximación teórica se atribuye a Hoover-Dempsey y colaboradores (1995). En líneas generales, este modelo pretende determinar los factores que explican que algunos padres y madres se impliquen más activa y frecuentemente que otros en la educación de sus hijos e hijas (Hoover-Dempsey, Walker y Sandler, 2005). Se entiende la implicación parental como un proceso influenciado por factores vinculados tanto a los propios padres y madres, como a los hijos e hijas y al centro escolar (Hoover-Dempsey y Sandler, 1995) (Figura 4), articulándose su análisis en los siguientes cinco niveles: 1) decisiones básicas de implicación por parte de los padres y madres; 2) elección de la forma de implicación por parte de los progenitores; 3) mecanismos de influencia de la implicación parental en los resultados escolares de los hijos e hijas; 4) variables moduladoras y 5) resultados del alumnado (Hoover-Dempsey y Sandler, 1997; Walker, Wilkins, Dallaire, Sandler y Hoover-Dempsey, 2005).

La lectura de este modelo se efectúa desde la parte inferior (Nivel 1: Parental Involvement Decision) a la superior (Nivel 5: Child/ Student Outcomes), advirtiéndose que un progenitor tenderá a

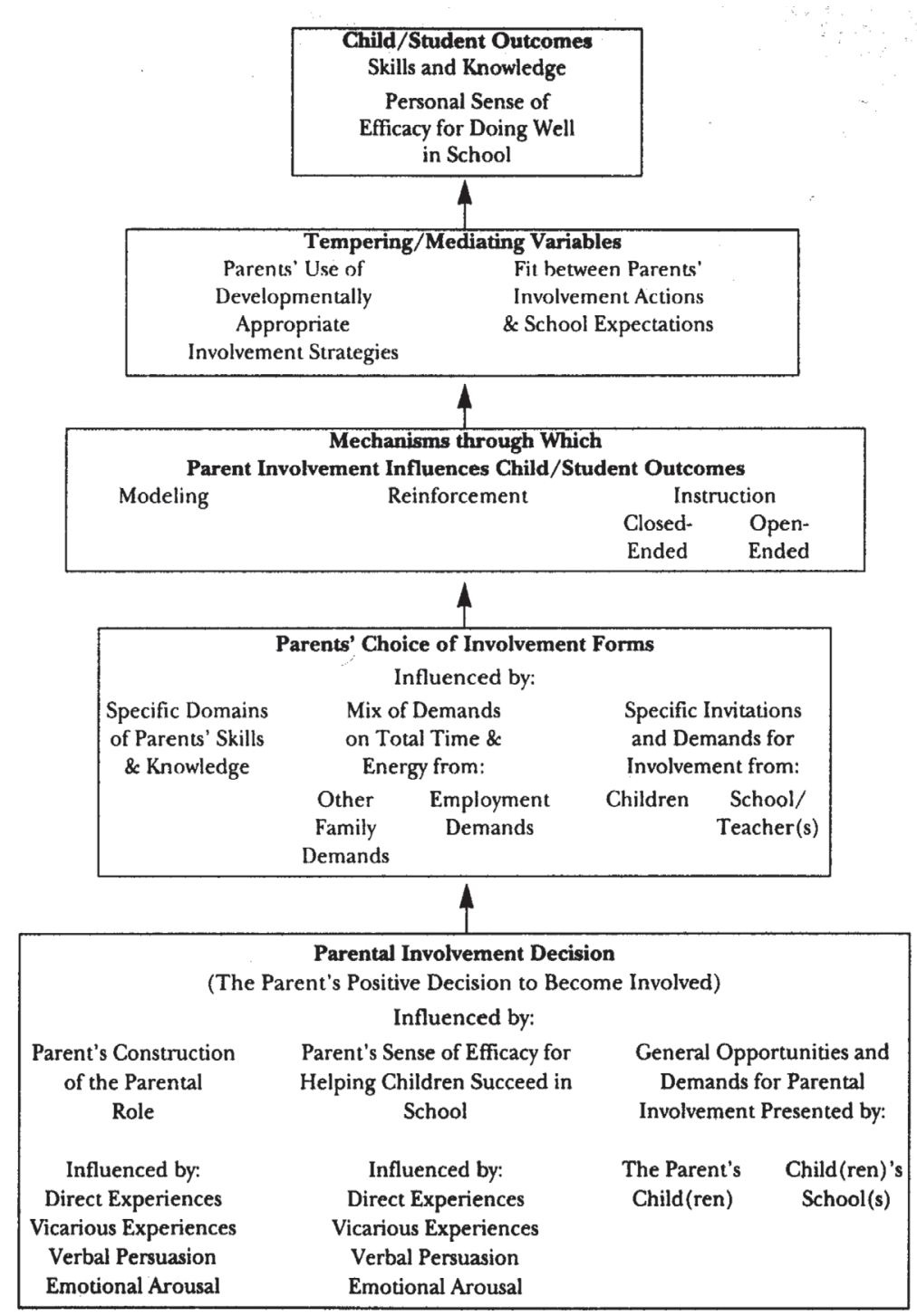

Figura 4. Modelo Causal y Específico de Implicación Parental. Fuente: Hoover-Dempsey y Sandler (1995, p.311) 
implicarse cuando perciba que su actuación pueda ser relevante y significativa en la educación de los y las menores, y cuando además aprecie que tanto el centro escolar como sus hijos o hijas esperan esta implicación. Hoover-Dempsey y Sandler (1997) focalizan su investigación en el desarrollo del primer nivel, revisando los siguientes condicionantes en el grado de implicación parental: 1) interiorización del rol parental; 2) sentimiento de eficacia parental para ayudar al hijo o hija a alcanzar el éxito educativo; y 3) oportunidades y demandas de implicación generadas tanto por parte de los propios padres y madres, como del centro escolar y de los hijos o hijas (Deslandes, 2001; Walker et al., 2005).

Por su parte, Hoover-Dempsey et al., 2001 y Walker, Hoover-Dempsey, Whetsel y Green (2005) formulan algunas propuestas a través de las que los padres y madres pueden apoyar eficaz- mente a sus hijos e hijas en su proceso escolar; para ello, necesitan el asesoramiento del profesorado y mantener relaciones con el centro. Estas propuestas se clasifican en dos secciones (Tabla 4): a) actividades que contribuyen a motivar a los niños y niñas hacia el estudio, que pueden ser desarrolladas en general por todos los progenitores, con independencia de sus competencias culturales, educativas, o de otro tipo, y b) estrategias que requieren conocimientos por parte de los padres y madres sobre el proceso de desarrollo de sus hijos e hijas y sobre el proceso de aprendizaje, así como de nociones sobre los contenidos curriculares. Para emplear estas estrategias se precisará que el centro escolar y el profesorado ofrezcan a las familias asesoramiento y pautas educativas a utilizar con sus hijos e hijas y promover en ellos y ellas el éxito escolar (Grant y Ray, 2013).

Tabla 4 .

Actividades y estrategias de implicación parental en el proceso académico de los hijos e hijas

\section{Sección A: Actividades}

- Interaccionar con el alumno/a, hijo/a y con el profesorado sobre las tareas escolares.

- Ofrecer unas condiciones físicas y psicológicas óptimas para el desarrollo de las tareas escolares.

- Desarrollar una supervisión general del proceso de realización de las tareas escolares en el hogar.

- Apoyar y ofrecer una respuesta ante posibles dudas planteadas por el estudiante/hijo e hija al realizar sus tareas escolares.

\section{Sección B: Estrategias}

- Participar en los procesos y tareas escolares del estudiante en el hogar.

- Participar en meta-estrategias diseñadas para crear un ajuste entre las tareas, habilidades, destrezas y el conocimiento del estudiantado.

- Implicarse en procesos interactivos de apoyo y orientación que faciliten la comprensión de las tareas escolares.

- Participar en meta-estrategias que ayuden al estudiante en el desarrollo de procesos de aprendizaje autónomo.
En definitiva, en el modelo que se acaba de revisar se vuelve a constatar la importancia de que exista una comunicación fluida y bidireccional entre el centro escolar y las familias (progenitores e hijos e hijas), considerando el impacto positivo que se produce tanto en el rendimiento académico del alumnado, clima relacional que se respira en el centro educativo y en el desarrollo de expectativas y actitudes parentales positivas hacia lo educativo y la convivencia en el hogar.

\section{Modelo Motivacional y de Conceptualización Multidimen- sional (Grolnick y Slowiaczek, 1994)}

Esta aproximación teórica es enriquecedora por abordar el análisis de la implicación educativa familiar desde una perspectiva ecológica, holística y multidimensional, que se aleja de la tradicional asociación entre este término, la educación formal y ayuda parental prestada en las actividades de aprendizaje del hijo e hija (Grolnick y Slowiaczek, 1994). Asimismo, ligando esta idea con el rendimiento académico y aprendizaje en general, Grolnick et al., (2007) insisten en este trabajo cooperativo, máxime cuando la investigación ha corroborado que además de contribuir a una mejor autorregulación del estudiante ante el aprendizaje, las dinámicas de aulas, centros escolares y familias que fomentan la autonomía en el alumnado/hijo e hija contribuyen a generar una mayor autopercepción de autonomía, de competencia personal y motivación intrínseca en este o esta.

Se trata de un modelo de predicción de la implicación parental en la educación de los hijos e hijas, considerando variables demográficas y tres niveles de análisis: individual, contextual familiar y contextual escolar, que influyen de manera diferencial en tres modalidades de implicación parental: personal, cognitivo-intelectual y escolar (Grolnick, Benjet, Kurowski y Apostoleris, 1997; Intxausti, 2010; Parra, 2011) (ver Figura 5). Según los estudios desarrollados por Grolnick y Slowiaczek (1994), las madres suelen mostrar niveles más elevados de implicación que los padres en todas las modalidades mencionadas.

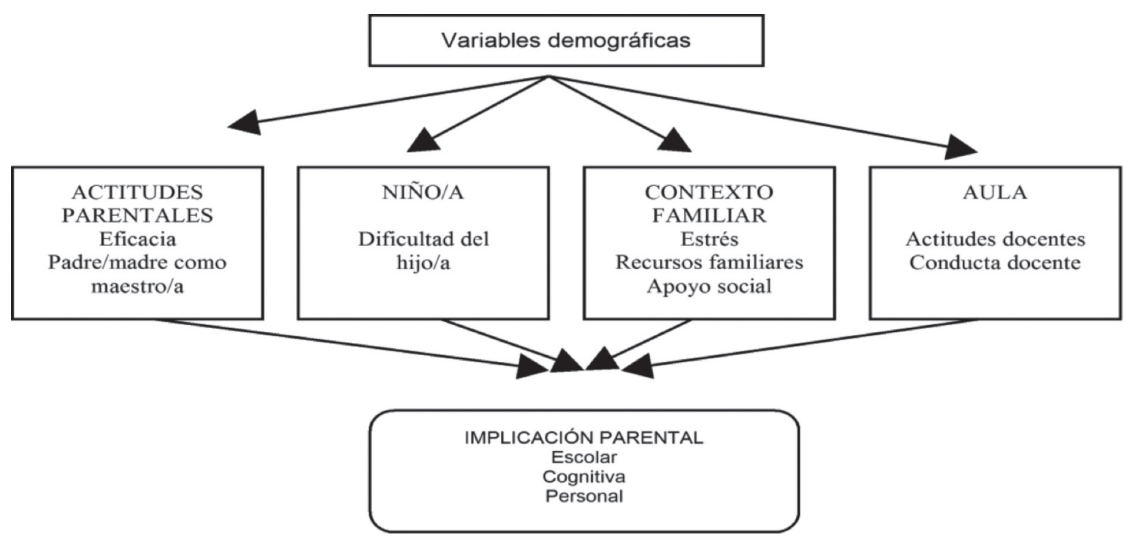

Figura 5. Factores hipotéticos de predicción de la implicación parental en la educación de los hijos e hijas. Fuente: Elaboración propia. 
El nivel de análisis de la esfera individual remite a las figuras de los progenitores y de los hijos e hijas, revisando tanto las creencias parentales de autoeficacia en el apoyo escolar a los hijos e hijas, como la percepción parental acerca de las conductas de estos, en cuanto a obediencia, colaboración, control, etc. Por su parte, el nivel de análisis contextual familiar incluye, entre otros aspectos, la vivencia (cantidad y calidad) de sucesos estresantes en la unidad familiar, redes de apoyo social, disponibilidad e idoneidad de los recursos familiares y la actitud de los progenitores para fomentar la autonomía en los hijos e hijas (Grolnick, 2009). Por último, el nivel de análisis contextual escolar se centra en valorar la importancia concedida por el profesorado a la implicación parental y la frecuencia con que se fomenta la colaboración con las familias desde el centro.

Por lo que respecta a las variables demográficas contempladas en este modelo, Intxausti (2010) y Parra (2011) indican que estas predicen la implicación parental cognitiva y escolar (mayor implicación cuando los padres y madres tienen un nivel social alto y cuando conviven en familias biparentales), pero no la implicación personal. A su vez, las variables individuales parentales de autoeficacia percibida en el rol parental predicen la implicación cognitiva: mayor implicación si existe una percepción de rol materno activo y eficaz. Las variables contextuales familiares también tienen capacidad predictiva: se observa menor implicación parental cuando hay más estrés parental y cuanto menores son los recursos de las familias. Además, en alusión al ejercicio parental, Grolnick y Pomerantz (2009) abogan por la influencia derivada de la estruc- tura y control parental en tanto que ambas condicionan la autonomía y sentimiento de competencia del hijo e hija, y consecuentemente su desarrollo y ajuste psicológico. Finalmente, por lo que respecta a la capacidad predictiva del centro escolar, se requiere planificar actividades de cooperación con las familias tomando en consideración su realidad social y cultural para fomentar en ellas una mejor actitud de colaboración (López, Ridao y Sánchez, 2004; Rivas y Ugarte, 2014; Simón et al., 2016).

\section{Modelo Bipiramidal Jerarquizado (Hornby, 1990)}

El último modelo objeto de análisis en este artículo conceptualiza la relación entre el centro escolar y las familias desde un enfoque comprensivo e integrador, resultante de la combinación de dos pirámides que contemplan, de manera jerarquizada, los recursos (parental contributions) y necesidades parentales (parental needs). De acuerdo con el modelo, la naturaleza de relaciones que cabe establecer varía en función de dos ejes: tiempo de que se disponga (parent/teacher time) y grado de especialización que se espera tanto de los propios padres y madres como del profesorado en función de las tareas a realizar (parent/teacher expertise) (Hornby, 1990, citado por Estévez, Jiménez y Musitu, 2007; Hornby, 2000). Se trata de un modelo útil al profesorado para fomentar la relación con las familias en la medida en que proporciona un marco de actuación variado, incluyendo desde propuestas de políticas educativas hasta planes y programas de formación de padres y madres (Figura 6).

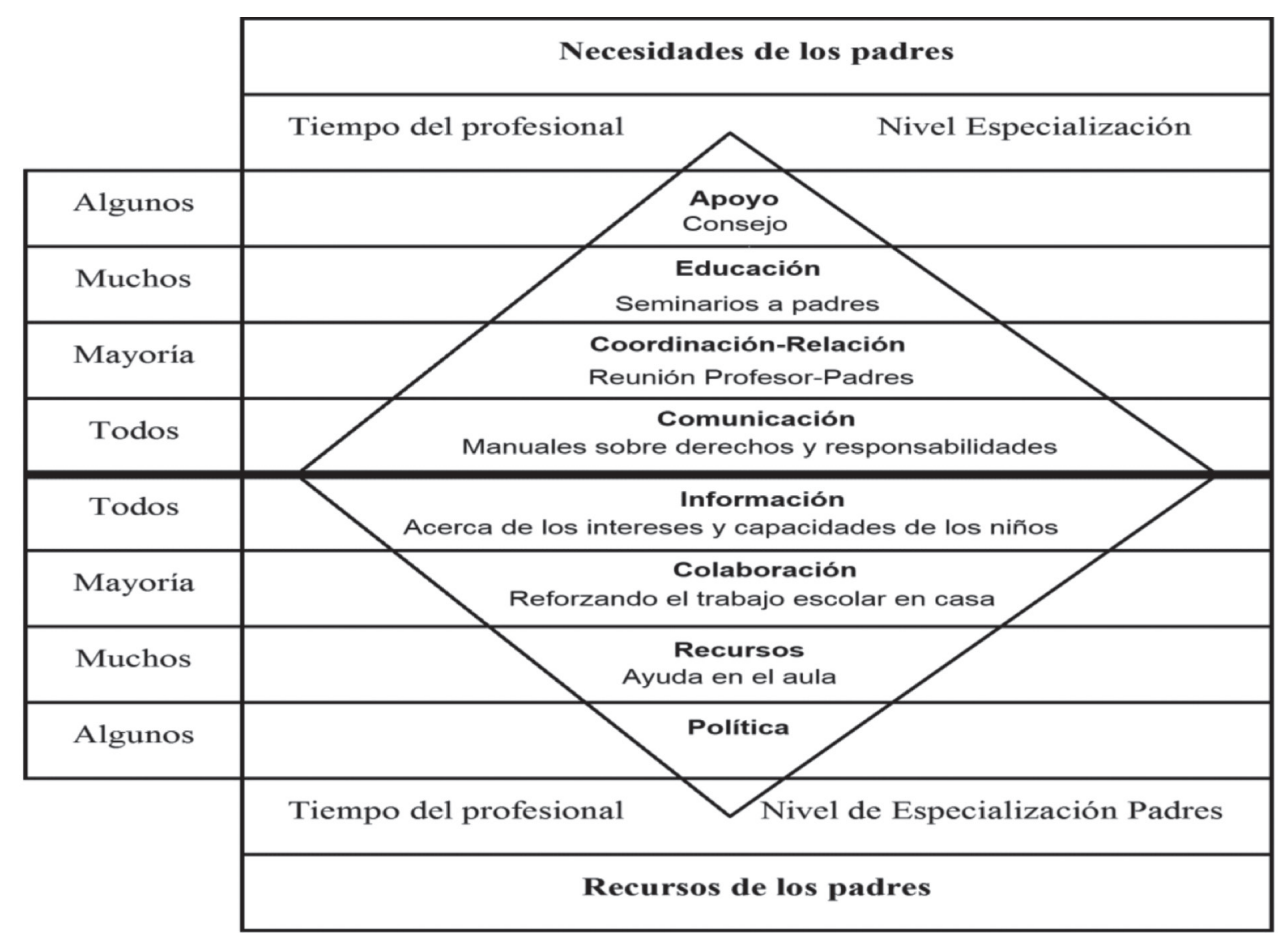

Figura 6. Modelo Bipiramidal Jerarquizado de Hornby (1990). Fuente: Estévez et al. (2007, p.71).

Siguiendo las aportaciones de_Hornby $(2000,2011)$ y Rivas (2007), entre los recursos y contribuciones que pueden aportar los padres y madres a los centros se encuentran las mencionadas en la Tabla 5.
Tabla 5.

Recursos parentales que integran el modelo Bipiramidal Jerarquizado

Información. Se entiende que los padres y madres son la fuente de información por excelencia sobre sus hijos e hijas en cuanto a intereses, rutinas, motivaciones... Cuando estos datos se comparten con el profesorado, la familia se siente escuchada y aprecia un interés real hacia la educación de su hijo o hija, lográndose 
también un desempeño profesional más ajustado a las necesidades de los y las estudiantes y, por tanto, más eficaz.

Colaboración. En ocasiones, la ayuda parental se extiende más allá de este intercambio de información sobre el hijo o hija, desarrollándose diferentes actividades de apoyo y complemento de la labor docente por parte de los padres y madres como, por ejemplo, fomentando la lectura en el hogar. Atendiendo a la diversidad familiar, se procurará que esta colaboración de las familias pueda desarrollarse conforme a sus posibilidades e intereses (Hornby, 2000).

Recursos. Otra valiosa contribución de la familia consiste en desarrollar actividades de ayuda y refuerzo al profesorado o a otros progenitores en las que se precisa de un tiempo, habilidades, destrezas, o conocimientos específicos que el padre/madre puede poseer en exclusividad. Con ello se cultiva la autoestima de los padres y madres y el enriquecimiento cultural y social de toda la comunidad educativa. En este punto, el autor del modelo aconseja la adquisición de habilidades de gestión y comunicación por parte del profesorado.

Gestión y normativa. Este apartado remite a una implicación parental activa en temas burocráticos o de toma de decisiones del centro (Rivas, 2007). Se trata de progenitores miembros de alguna asociación, organización, consejos, etc. relacionados con el ámbito educativo y que, por tanto, pueden compartir su experiencia propia en un campo de saber (teórico o empírico) concreto. También se incluye aquí la colaboración prestada por algún padre y/o madre para redactar informes y/o artículos, implementar talleres, etc.

Por otro lado, entre las necesidades parentales a contemplar por los centros, formuladas por Hornby (2000) se encuentran las enumeradas en la Tabla 6.

Tabla 6.

Necesidades parentales que integran el modelo Bipiramidal Jerarquizado

Comunicación. Estamos ante una de las necesidades más acuciantes de los progenitores: el derecho a estar informados sobre la marcha académica de sus hijos e hijas en el centro escolar: rendimiento académico, comportamiento, posibles dificultades... Así, se intentará reforzar la confianza y cercanía de las familias, difundiendo la idea de "apertura real del centro a los padres/ madres" durante todo el curso escolar.

Coordinación. Los padres y madres ven en los docentes una fuente de respuesta a las inquietudes y preocupaciones que les surgen con respecto a la educación de sus hijos e hijas. Así las cosas, y aunque los encuentros personales familia-docentes suelen ser la modalidad más recurrente para este intercambio informativo, Hornby (2000) aconseja que el profesorado también promueva encuentros formales e informales con las familias, especialmente con aquellas que más dificultad encuentran para asistir al centro.

Educación Familiar. Desde distintos foros se insiste en el interés de dar respuesta a las dudas y demandas planteadas por los padres y madres al afrontar la educación de sus hijos e hijas (López et al., 2004; Martínez-González, Álvarez y Pérez, 2010; Rivas, 2007). Ante estas situaciones, uno de los agentes aliados es el centro escolar a través de la organización de Escuelas de Familias, talleres o seminarios donde las familias intercambien sus experiencias, preocupaciones, perspectivas, etc. (Martínez-González, 2009).

Apoyo. Siendo cada vez más elevado el número de padres y madres que demandan un asesoramiento en el ejercicio positivo de su rol parental, las familias suelen demandar ayuda a la institución académica (Hornby, 2000). Se aconseja entonces que el profesorado posea unas adecuadas habilidades de comunicación para asesorarlas o bien para derivarlas a otros profesionales específicos.

Tomando en consideración los recursos y necesidades parentales, citados por Hornby (2000), se puede efectuar una reflexión y diagnóstico del centro escolar en materia de colaboración con las familias, revisando las actividades que se promueven y cuáles no, qué niveles de implicación se están obteniendo en cada caso y qué grado de satisfacción se ha alcanzado.

\section{Conclusiones}

Las familias y los centros escolares tienen un marcado protagonismo en la educación de los menores, evidenciando la investigación que la calidad de sus relaciones influye en su éxito académico. Aún advirtiéndose en ambos contextos características y dinámicas diferentes de funcionamiento, ambos agentes educativos comparten el objetivo común de fomentar las mejores condiciones para su desarrollo integral. De ahí que sea necesario promover iniciativas que dinamicen las relaciones entre las familias, los centros escolares, extendiendo también esta colaboración a las entidades del entorno comunitario (Sreekanth, 2010). Se trata con ello de adoptar un enfoque eminentemente preventivo mediante el que dar una respuesta de calidad educativa al alumnado, en especial a aquel que presenta dificultades de aprendizaje (Robledo y García, 2009), de adaptación al centro, repetición de curso (Veiga et al., 2015) y que está en riesgo de fracaso o de abandono escolar (Álvarez y Martínez-González, 2017b; Martínez-González et al., 2008). En este artículo se han presentado diversas aproximaciones teóricas (modelos) sobre cómo se pueden entender y dinamizar tanto las relaciones entre los centros y las familias, como la implicación familiar en los procesos educativos de los hijos e hijas (González-Pienda y Núñez, 2005) con una doble aspiración: 1) dotar a estos últimos de mejores oportunidades de promoción y desarrollo y 2) rentabilizar los recursos invertidos a nivel profesional, material, económico, de tiempos y esfuerzo -dedicación- (Méndez y Cerezo, 2018).

Efectuando un análisis comparativo entre la relación de modelos expuestos, se entiende que dos de los principales aspectos en que convergen los seis modelos revisados son, primeramente, la constatación de que la educación se concibe como el producto resultante de iniciativas, responsabilidades y esfuerzos compartidos, al menos, por tres instancias: familia, centro escolar y entorno comunitario (Epstein, 2011). En segundo lugar sobresale la adopción de un enfoque sistémico conforme el cual los diferentes elementos $\mathrm{y}$ agentes interaccionan, ejerciendo y recibiendo influencias mutuas en un flujo constante de comunicación y reacomodación.

Asimismo, estas aproximaciones teóricas plantean la ejecución preliminar de un proceso de diagnóstico o reflexión sobre los componentes que integran cada modelo con el objetivo de describir, explicar y comprender los indicadores y patrones endógenos y exógenos que son inherentes a la citada implicación educativa familiar. Con ello, tras este procedimiento se aspira a identificar los factores de riesgo y protección que ayuden a potenciar tanto el aprovechamiento y rendimiento académico como a prevenir una prematura deserción escolar.

Por su parte, en las experiencias de cooperación familiar a las que se está aludiendo, los centros escolares, las familias y la comunidad focalizan su atención en la figura del estudiante/sujeto en proceso de desarrollo y aprendizaje. Así pues, las principales discrepancias entre los modelos teóricos revisados en este artículo radican en el orden de aparición de los agentes participantes y en el peso y protagonismo concedido a cada uno de ellos en la comprensión de la implicación educativa familiar. En este orden de cosas, los modelos "Motivacional y de Conceptualización Multidimensional" y el "Causal y Específico de Implicación Parental" difieren de las restantes aproximaciones teóricas en la exhaustividad y notable concreción con que se presentan y describen sus elementos integrantes. 
Se concluye señalando que solamente dos de los seis modelos analizados, el "Bipiramidal Jeraquizado" y el "Syneducation" contemplan como punto de partida la realización de una detección de necesidades de los diversos agentes implicados, circunstancia que se valora como muy positiva al permitir ajustar cualquier intervención socio-psicoeducativa o propuesta de fomento de la implicación educativa familiar (Felizardo et al., 2016) a la idiosincrasia de uno o varios espacios convivenciales, participantes y, en consecuencia, a sus potencialidades, limitaciones y demandas específicas de asesoramiento y/o apoyo (Estévez y Musitu, 2016).

Como conclusión de todo lo expuesto, este artículo pone de relieve el interés de abogar por una complementariedad de los modelos teóricos desde los que se estudie la cooperación entre el ámbito familiar, escolar y comunitario, insistiéndose en que esta se construya cada día (Malvar, 2007; Martínez-González y Álvarez, 2005) y sea considerado un tema prioritario en todas los proyectos educativos de centro, en la práctica cotidiana de los centros escolares y, especialmente, en las políticas y acuerdos educativos que se promulguen y adopten (Fernández, 2018).

\section{Referencias bibliográficas}

Aguilera, J. C., y Rodríguez, A. (2010). Principios de subsidiariedad y equidad en la gestión de las organizaciones educativas. Comunicación presentada en el Congreso Iberoamericano de Educación. Metas 21, Buenos Aires, 13, 14 y 15 de septiembre de 2010.

Ainscow, M. (2016). Collaboration as a strategy for promoting equity in education: possibilities and barriers. Journal of Professional Capital and Community, 1(2), 159-172.

Álvarez, L. (2006). Familia y abandono escolar. Importancia de la implicación familiar en el sistema educativo. Madrid: Cinca.

Álvarez, L., y Martínez-González, R. A. (2016). Cooperación entre las familias y los centros escolares como medida preventiva del fracaso y del riesgo de abandono escolar en adolescentes. Revista Latinoamericana de Educación Inclusiva, 10(1), 175-192. doi:10.4067/S0718-73782016000100009

Álvarez, L., \& Martínez-González, R. A. (2017a). Review of the Partnership between School and Family: A Shared Responsibility. In J. A. González-Pienda, A. Bernardo, J. C. Nuñez \& C. Rodríguez (Eds.), Factors affecting academic performance (pp. 121-140). New York: Nova Science Publishers.

Álvarez, L., y Martínez-González, R. A. (2017b). Percepción docente de la adaptación escolar del alumnado en riesgo de abandono. Temas de Educación, 23(2), 232.

Álvarez, A., Suárez, N., Tuero, E., Núñez, J. C., Valle, A., y Regueiro, B. (2015). Implicación familiar, autoconcepto del adolescente y rendimiento académico. European Journal of Investigation in Health, Psychology and Education, 5(3), 293-311. doi:10.30552/ejihpe.v5i3.133

Alves, A. F., Assis, C. M., Martins, A., \& da Silva, L. (2017). Cognitive Performance and academic achievement: How do family and school converge? European Journal of Education and Psychology, 10, 49-56. doi: https://doi.org/10.1016/j.ejeps.2017.07.001

Bertalanffy, L. V. (1968). General System Theory. Foundations, Development, Applications. New York, N.Y.: George Braziller.

Bronfenbrenner, U. (1987). La ecología del desarrollo humano. Barcelona: Paidós.

Bronfenbrenner, U. (1999). Environments in developmental perspective: theoretical and operational models. In S.L. Friedman (Ed.), Measuring environment across the life span: emerging methods and concepts (pp. 3-38). Washington, DC: American Psychological Association.
Bronfenbrenner, U. (2005). Making Human Beings Human. Bioecological Perspectives on Human Development. Thousand Oaks: Sage.

Bronfenbrenner, U., \& Morris, P. (1998). The ecology of developmental process. In W. Damon \& R. M. Lemer, Handbook of child psychology: Vol. I. Theoretical models of human development (pp. 993-1028). New York: John Wiley.

Calero, J., Choi, A., y Waisgrais, S. (2010). Determinantes del riesgo de fracaso escolar en España: una aproximación a través de un análisis logístico multinivel aplicado a PISA-2006. Revista de Educación, Número extraordinario, 225-256.

Cerezo, M. T., y Casanova, P. F. (2004). Diferencias de género en la motivación académica de los alumnos de Educación Secundaria Obligatoria. Revista Electrónica de Investigación Psicoeducativa y Psicopedagógica, 2(1), 97-112.

Coe, J. L., Davies, P. T., \& Sturge-Apple, M. L. (2017). The multivariate roles of family instability and interparental conflict in predicting children's representations of insecurity in the family system and early school adjustment problems. Journal of Abnormal Child Psychology, 45(2), 211-224. doi:10.1007/ s10802-016-0164-6

Christenson, S. L., \& Reschly, A. M. (Eds.). (2010). Handbook of School-Family Partnerships. New York: Routledge.

De la Riva, F., y Moreno, A. (2018). Una experiencia de educación para la participación. Communiars: Revista de Imagen, Artes y Educación Crítica y Social, 1, 43-51.

Deslandes, R. (2001). A vision of home-school partnership: three complementary conceptual frameworks. In F. Smit, K. Van der Wolf \& P. Sleegers, A bridge to the future. Collaboration between parents, schools and communities (pp. 11-23). Nijmegen: ITS, Stichting Katholucke Universiteit te Nijmegen.

Deslandes, R. (2015). Collaboration famille-école-communauté pour une inclusion réussie. In N. Rousseau et S. Bélanger (Dir.), La pédagogie de l'inclusion scolaire (pp. 203-232). Sainte-Foy, Québec : Presses de l'Université du Québec.

Díaz-Aguado, M. J., Martínez, M. R., y Ordoñez, A. (2013). Prevenir la drogodependencia en adolescentes y mejorar la convivencia desde una perspectiva escolar ecológica. Revista de Educación, 1, 338-362. doi: 10.4438/1988-592X-RE-2013EXT-251

Estévez, E., y Musitu, G. (Coords.). (2016). Intervención psicoeducativa en el ámbito familiar, social y comunitario. Madrid: Ediciones Paraninfo.

Epstein, J. (1987). Towards a theory of family-school connections: teacher practices and parental involvement. In K. Hurrelmann, F.X. Kausfmann \& F. Lösel, Social intervention: potential and constraints (pp.121-136). Berlin \& New York: Walter de Gruyter.

Epstein, J. L. (1990). School, family and community partnership. Thousand Oaks, C.A: Corwin Press, INC.

Epstein, J. L. (1995). School, family, community partnership: caring for the children we share. Phi, Delta Kappan, 76, 701-712.

Epstein, J., Sanders, M., Simon, B., Salinas, K., Jansorn, N., \& Van Voorhis, F. (2002). School, family, and community partnerships: Your handbook for action. Thousand Oaks, CA: Corwin Press.

Epstein, J. (2011). School, family and community partnerships: preparing educators and improving schools. Boulder, CO: Westview Press.

Epstein, J. L., \& Salinas, K. C. (2004). Partnering with families and communities. Educational Leadership, 61(8), 12-18.

Epstein, J. L., \& Sanders, M. G. (2006). Prospects for change: preparing educators for school, family and community partnership. Peabody Journal of Education, 81(2), 81-120.

Epstein, J. L., \& Sheldon, S. B. (2002). Present and accounted for: improving student attendance through family and 
community involvement. Journal of Educational Research, 95(5), 308-318.

Estévez, E.; Jiménez, T., y Musitu, G. (2007). Relaciones entre padres e hijos adolescentes. Valencia: Nau Llibres.

Felizardo, S., Cantarinha, D., Alves, A. B., Ribeiro, E. J., \& Amante, M .J. (2016). Students' involvement in school and parental support: Contributions to the socio-educational intervention. The European Proceedings of Social E Behavioural Sciences, 21, 278-287. doi: http://dx.doi.org/10.15405/epsbs.2016.11.29

Fernández, M. (2018). Bases para acordar el futuro de la educación. Cuadernos de Pedagogía, 488, 74-78.

Fernández-Zabala, A., Goñi, E., Camino, I., \& Zulaika, L. M. (2016). Family and school context in school engagement. European Journal of Education and Psychology, 9(2), 47-55. doi:10.1016/j.ejeps.2015.09.001

Fletcher, R., \& Silberberg, S. (2006). Involvement of fathers in Primary school activities. Australian Journal of Education, 50(1), 29-39.

Fuentes, M. C., García, F., Gracia, E., y Alarcón, A. (2015). Los estilos parentales de socialización y el ajuste psicológico. Un estudio con adolescentes españoles. Revista de Psicodidáctica, 20(1), 117-138. doi: 10.1387/RevPsicodidact.10876

García, M. P., Hernández, M. A., Parra, J., y Gomáriz, M. A. (2016). Participación familiar en la etapa de Educación Primaria. Perfiles Educativos, 38(154), 97-117.

Gârțu, M. L. (2017). The School-Family Educational Partnership. Journal of Pedagogy, 2, 107-123. doi: https://doi.org/10.26755/ RevPed/2017.2/107

Gifre, M., y Esteban, M. (2012). Consideraciones educativas de la perspectiva ecológica de Urie Bronfenbrenner. Contextos Educativos, 15, 79-92.

Grau, R.; Pina, T., y Sáncho, C. (2011). Posibles causas del fracaso escolar y el retorno al sistema educativo. Hekadamos, Revista Educativa Digital, 9, 55-76.

Gertrudis, M; Gértrudix, M., y Álvarez, S. (2016). Competencias informativas profesionales y datos abiertos. Retos para el empoderamiento ciudadano y el cambio social. Revista Comunicar, 47, 39-47. doi: http://dx.doi.org/10.3916/C47-2016-04

González, S., García, Ma P., Ruiz, F., y Muñoz, J. M. (2015). Factores de riesgo del abandono escolar desde la perspectiva del profesorado de Educación Secundaria Obligatoria en Andalucía (España). Profesorado: Revista de Curriculum y Formación del Profesorado, 19(3), 226-245.

González-Pienda, J. A., y Núñez, J. C. (2005). La implicación de los padres y su incidencia en el rendimiento de los hijos. Revista de Psicología y Educación, 1(1), 115-134.

Grant, K., \& Ray, J. A. (2013). Home, school and community collaboration. Culturally responsive family engagement. Los Ángeles, CA: Sage.

Grau, R., Pina, T., y Sancho, C. (2011). Posibles causas del fracaso escolar y el retorno al sistema educativo. Hekademos, 9, 55-76.

Grolnick, W. S. (2009). The role of parents in facilitating autonomous self-regulation for education. Theory and Research in Education, 7(2), 164-173.

Grolnick, W. S.; Benjet, C.; Kurowski, C. O., \& Apostoleris, N. H. (1997). Predictors of Parent involvement in Children's Schooling. Journal of Educational Psychology, 89(3), 538-548.

Grolnick, W. S.; Farkas, M.; Sohmer, R.; Michaels, S., \& Valsiner, J. (2007). Facilitating motivation in young adolescents: effect of an after-school program. Journal of Applied Developmental Psychology, 28, 332-344.

Grolnick, W. S., \& Pomerantz, E. M. (2009). Issues and challenges in studying parental control: toward a new conceptualization. Child Development Perspectives, 3(3), 165-170.
Grolnick, W.S., \& Slowiaczek, M. L. (1994). Parents' involvement in children's schooling. A multidimensional conceptualization and motivational model. Child Development, 65, 237-252.

Hayes, N., O’Toole, L., \& Halpenny, A. M. (2017). Introducing Bronfenbrenner. A guide for practicioners and students in early years education. London \& New York: Routledge.

Hill, N. E., \& Tyson, D. F. (2009). Parental involvement in middle school: A meta-analytic assessment of the strategies that promote achievement. Developmental Psychology, 45(3), 740-763. doi: $10.1037 / \mathrm{a} 0015362$

HoltIS, UNICEF (2017). Tipuri de suport parental. Ghid pentru încurajarea parentingului apreciativ (Types of Parental Support. A Guide for Encouraging Appreciative Parenting). Iaşi: Editura Expert Projects.

Hoover-Dempsey, K; Battiato, A.; Walker, J.; Reed, R.; DeJong, J., \& Jones, K. (2001). Parental Involvement in Homework. Educational Psychologist, 36(3), 195-209.

Hoover-Dempsey, K., \& Sandler, H. M. (1995). Parental involvement in children's education: why does it make a difference? Teachers College Record, 97(2), 310-331.

Hoover-Dempsey, K., \& Sandler, H. M. (1997). Why do parents become involved in their children's education? Review of Educational Research, 67, 3-42.

Hoover-Dempsey, K.; Walker, J., \& Sandler, H. (2005). Parents' motivations for involvement in their children's education. In E. N. Patrikakou, R. P. Weisberg, S. Redding \& H. J. Walberg (Eds.), School-Family Partnerships for Children's Success (pp. 4056). New York: Teachers College Press.

Hornby, G. (2000). Improvement Parental Involvement. London: Continuum.

Hornby, G. (2011). Parental Involvement in Childhood Education. Buiding Effective School- Family Relationships. London: Springer.

Intxausti, N. (2010). Expectativas e implicación educativa de las familias inmigrantes de escolares en Educación Primaria de la CAPV: bases para la intervención educativa. Tesis doctoral. San Sebastián: Universidad del País Vasco.

Jiménez, A., y Moreno, M. C. (2015). La influencia de las diferencias entre el padre y la madre sobre el ajuste adolescente. Anales de Psicología, 31(1), 367-377. doi:10.6018/analesps.31.1.158081

López, I., Ridao, P., y Sánchez, J. (2004). Las familias y las escuelas: una reflexión acerca de entornos educativos compartidos. Revista de Educación, 334, 143-163.

Malvar, M ${ }^{\mathrm{a}}$ L. (2007). Familia e escola, comparten a mesma linguaxe. En $M^{a}$ D. Fernández (Ed.), Familia e escola: encontro vs desencontro (pp.79-83). Santiago de Compostela: Departamento de Didáctica e Organización da USC e Fundación Preescolar na Casa.

Marchesi, A., y Pérez, E. (2003). La comprensión del fracaso escolar. En A. Marchesi y C. Hernández, (Coords.), El fracaso escolar. Una perspectiva internacional (pp. 25-50). Madrid: Alianza Editorial.

Martínez-González, R. A. (1997). Experiencia de investigaciónacción para analizar las necesidades de cooperación entre las familias y los centros escolares. Bordón, 49(2), 155-163.

Martínez-González, R. A. (2009). Programa-Guía para el Desarrollo de Competencias Emocionales, Educativas y Parentales. Madrid: Ministerio de Sanidad y Política Social.

Martínez-González, R. A., y Álvarez, L. (2005). Fracaso y abandono escolar en educación secundaria obligatoria: implicación de la familia y los centros escolares. Aula Abierta, 85, 127-146.

Martínez-González, R. A., Álvarez, L., y Pérez, M. H. (2010). Programa-Guía para el desarrollo de competencias emocionales, 
educativas y parentales. Papeles Salmantinos de Educación, 14, 63-88.

Martínez-González, R. A., Pereira, M., Rodríguez, B., Peña del Agua, A., Martínez, R., García, M.P, y Casielles, V. (2000). Dinamización de las relaciones familia-centro escolar a través de la formación del profesorado en este campo de actuación. Revista Española de Orientación y Psicopedagogía, 11(19), 107120.

Martínez-González, R. A., y Pérez, M. H. (2004). Evaluación e intervención educativa en el campo familiar. Revista Española de Orientación y Psicopedagogía, 15(1), 89-104.

Martínez-González, R. A., y Pérez, M. H. (2006). Propuestas metodológicas para una educación de calidad a través de las relaciones entre centros docentes, familias y entidades comunitarias. Cultura y Educación, 18(3-4), 231-246.

Martínez-González, R. A., Rodríguez-Ruiz, B., Álvarez-Blanco, L., \& Becedóniz-Vázquez, C. (2016). Evidence in promoting positive parenting through the Program-Guide to Develop Emotional Competences. Psychosocial Intervention, 25, 111117. doi:10.1016/j.psi.2016.04.001

Martínez-González, R. A.; Rodríguez, B., y Gimeno, J. L. (2010). Áreas de cooperación entre los centros docentes y las familias: estudio de caso. Educatio siglo XXI: Revista de la Facultad de Educación, 28(1), 127-156.

Martínez-González, R. A., y San Fabián, J.L. (2002). Autoevaluación de la cultura participativa del centro. Organización y Gestión Educativa, 4, 19-26.

Martínez-González, R. A., Symeou, L., Álvarez-Blanco, L., Roussounidou, E., Iglesias-Muñiz, J., \& Cao-Fernández, M.A. (2008). Family involvement in the education of potential drop-out children: a comparative study between Spain and Cyprus. Educational Psychology, 28(5), 505-520.

Méndez, I., y Cerezo, F. (2018). La repetición escolar en Educación Secundaria y factores de riesgo asociados. Educación XX1, 21(1), 41-62. doi: 10.5944/educXX1.13717

Moreno, E. (2002). La familia como institución sociocultural. Su papel en la adquisición de hábitos lectores. Portularia, 2, 309324.

Mylonakou, I., \& Kekes, I. (2005). Syneducation (Synekpaidefsis): Reinforcing Communication and Strengthening Cooperation among Students, Parents and Schools. Harvard Family Research Project, March, 1-9. Harvard Graduate School of Education: Cambridge.

Mylonakou, I., \& Kekes, I. (2007). School, Family and the Community in cooperation: The model of Syneducation. International Journal about Parents in Education, 1(0), 73-82.

Parra, C. (2011). Educación inclusiva: un modelo de diversidad humana. Revista Educación y Desarrollo Social, 1, 139-150.

Ramos, D., y Arévalo, M. G. (2018). La prevalencia de la sociedad del conocimiento o la sociedad de la información como elementos estructurantes del sistema social. Prisma Social: Revista de Investigación Social, 20, 333-346.

Redding, S. (2006). Qué piensan padres y profesores de la escuela y unos de otros. Cultura y Educación, 18(3-4), 268-281.
Rivas, S. (2007). La participación de las familias en la escuela. Revista Española de Pedagogía, 238, 559-574.

Rivas, S., y Ugarte, C. (2014). Formación docente y cultura participativa del centro educativo: claves para favorecer la participación familia-escuela. ESE: Estudios sobre Educación, 27, 153-168. doi: 10.15581/004.27.153-168

Robledo, P., y García, J. N. (2009). El entorno familiar y su influencia en el rendimiento académico de los alumnos con dificultades de aprendizaje: revisión de estudios empíricos. Aula Abierta, 37(1), 117-128.

Robledo, P., y García, J. N. (2011). El papel de la familia en los resultados académicos. En J. M. Román, M. A. Carbonero y J. D. Valdivieso (Comps.), Actas del Congreso Educación, Aprendizaje y Desarrollo en una sociedad multicultural (pp. 9483-9494). Madrid: Asociación de Psicología y Educación.

Rodrigo, Ma․ J., Máiquez, M. L., Martín, J. C., Byrne, S., y Rodríguez, B. (Eds.). (2015). Manual práctico de parentalidad positiva. Madrid: Síntesis.

Rodrigo, Maㅡ. J., Martínez-González, R. A., y Rodríguez-Ruiz, B. (2018). La relación centro escolar-familia como factor protector de conductas transgresoras en la adolescencia. Aula Abierta, 47(2), 149-158. doi: https://doi.org/10.17811/rifie.47.2.2018.149-158

Sarramona, J., y Rodríguez, T. (2010). Participación y calidad de la educación. Aula Abierta, 38(1), 3-14.

Simón, C., Giné, C., y Echeita, G. (2016). Escuela, familia y comunidad: construyendo alianzas para promover la inclusión. Revista Latinoamericana de Educació Inclusiva, 10(1), 25-42.

Sreekanth, Y. (2010). Parents involvement in the education of their children: indicators of level of involvement. International Journal About Parents in Education, 5(1), 36-45.

Suárez, P. A., y Vélez, M. (2018). El papel de la familia en el desarrollo social del niño: una mirada desde la afectividad, la comunicación familiar y estilos de educación parental. Revista Psicoespacios, 12(20), 173-198.

Valle, A., Núñez, J. C., Piñeiro, I., Rodríguez, S., y Rosario, P. (2018). Niveles de rendimiento académico e implicación en los deberes escolares en estudiantes españoles de Educación Secundaria. European Journal of Education and Psychology, 11(1), 19-31. doi:10.30552/ejep.v11il.183

Veiga, F., García, F., Reeve, J., Wentzel, K., \& García, Ó. (2015). When adolescents with high self-concept lose their engagement in school. Revista de Psicodidáctica, 20(2), 305-320. doi:10.1387/RevPsicodidact.12671

Walker, J., Hoover-Dempsey, K. V., Whetsel, D. R., \& Green, C. (2004). Parental involvement in homework: A review of current research and its implications for teachers, after school program staff, and parent leaders. Cambridge, MA: Harvard Family Research Project.

Walker, J. M. T.; Wilkins, A. S.; Dallaire, J. R.; Sandler, H. M., \& Hoover-Dempsey, K. V. (2005). Parental Involvement: model revision through scale development. The Elementary School Journal, 106(2), 85-104.

Xu, Y., \& Filler, J. (2008). Facilitating family involvement and support for inclusive education. The School Community Journal, 18(2), 53-71. 